\title{
Perceptions of teenage women about marriage in adolescence in an Iranian setting: A qualitative study
}

\author{
Afrouz Mardi ${ }^{1,2}$, Abbas Ebadi $^{3}, Z_{\text {Zahra Behboodi Moghadam }}^{4}$, Shirin Shahbazi ${ }^{5}$
}

${ }^{1}$ Ph.D. Candidate in Reproductive Health, School of Nursing and Midwifery, Tehran University of Medical Science, Tehran, Iran

${ }^{2}$ Lecturer, School of Health, Ardabil University of Medical Sciences, Ardabil, Iran

${ }^{3}$ Professor in Nursing, Behavioral Sciences Research Center, Nursing Faculty, Baqiyatallah University of Medical Sciences, Tehran, Iran

${ }^{4}$ Ph.D. in Reproductive Health, Associate Professor, School of Nursing and Midwifery, Tehran University of Medical Science, Tehran, Iran

${ }^{5}$ Ph.D. in Reproductive Health, Assistant Professor, School of Nursing and Midwifery, Tehran University of Medical Science, Tehran, Iran

\section{Type of article: Original}

\begin{abstract}
Background and aim: Early marriage threatens the health and human rights of millions of girls all around the world. The aim of this study was to explore the perceptions of Iranian teenage women about marriage in adolescence.

Methods: A qualitative study was conducted based on the conventional content analysis approach on 14 teenage married women (aged13-19 years) who attended all urban-rural healthcare centers (4 centers) in Ardabil, Iran between May 2016 and Jan 2017. Data were collected through in-depth semi-structured interviews. Purposeful sampling was continued until data saturation. The data were analyzed using the Graneheim and Landman strategies.

Results: The mean age at marriage was $13.2(\mathrm{SD}=1.25)$ years and the duration of marital life ranged from 45 days to 3 years. During the data analysis, three main categories were extracted that each of them consisted of three sub-categories. The main categories, included "a false sense of sexual development", "death of dreams", and "threatened independence".

Conclusion: Results of this study revealed that teenage women could not comprehend opportunities in life. These findings could help health care providers and policy makers to provide teenage women with special care and better support to prevent negative consequences of early marriage.

Keywords: Marriage, Perception, Adolescence, Women, Qualitative study
\end{abstract}

\section{Introduction}

Despite the alarming trend of increased marriage age in many societies, early marriage is still a serious issue and a form of violence against girls that has not been dealt with as it should (1). By definition, child marriage is a marriage in which the wife or husband or both are under the age of 18. This bitter fact threatens the health and human rights of millions of girls worldwide, and in developing countries in particular. One-third of girls in the developing countries marry below the age of 18 years. Between 2011 and 2020, 14.2 million children are expected to marry worldwide every year and this figure will be 15.1 million between 2021 and 2030 (25,000 cases every day) (2, 3). These young girls are often called "women" because of their marriage, while they are still children in terms of age and experience (1). According to religious rules which are derived from Islam, boys and girls should marry as soon

\section{Corresponding author:}

Associate Professor Dr. Zahra Behboodi Moghadam, School of Nursing and Midwifery, Tehran University of Medical Science, Tohid Square, Eastern-Nosrat Street, Tehran 1419733171, Iran.

Tel: +98.9122494201,Fax:+98.2188363715, Email: bahar_behboodi@yahoo.com

Received: October 05, 2017, Accepted: January 10, 2018, Published: February 2018

iThenticate screening: January 07, 2018, English editing: January 14, 2018, Quality control: January 15, 2018

This article has been reviewed / commented by four experts

(C) 2018 The Authors. This is an open access article under the terms of the Creative Commons Attribution-NonCommercialNoDerivs License, which permits use and distribution in any medium, provided the original work is properly cited, the use is non-commercial and no modifications or adaptations are made. 
as possible. In addition to religious approval, traditional values of the family and patriarchy are some of the causes of early marriage (4). There is no age limitation for marriage in Iran and the father or compulsory guardian may force his under 13-year-old daughter to marry after securing permission from the court of law (5). Statistics show that the main age range of marriage in Iran, has been 20-24 and 15-19 years in men and women since 2010, respectively (6). Although this phenomenon is rarely found in large cities, it is still observed in some urban areas, and is more common in rural societies. Parents in poor rural families perceive their girl's marriage as a way to decrease family costs of living and also provide support and security for their girl (4). It is believed that a young bride adapts to the terms of the husband's family much easier than older brides (7). Child marriage is in contrary to the Convention on the Rights of the Child, and threatens the realization of the goals of sustainable development such as healthy life, better welfare at all ages, gender equality, stable economic growth, decent occupation, high quality education, and elimination of poverty and hunger $(8,9)$. Early marriage accelerates the change from childhood to adulthood, so that the girl, despite being a child, must play the roles of a mother and a wife without the required autonomy or ability to make decisions (10). Teenage women are socially vulnerable as they are mostly poor, uneducated, and rural, and have limited access to health care services (11). These girls are often forced to quit school, and opportunities for education, intellectual development, a decent job, financial independence, and a move out of poverty are all stolen from them (7). They are entrapped in a vicious circle of poverty with limited access to family and social support and a high risk of depression, inability and divorce (12). Child marriage means early initiation of sexual relations, pregnancy and delivery. High mortality rate (13), high-risk and illegal abortion (14), preterm labor, low birth weight, pre-eclampsia, obstetric fistula, hemorrhage, dystocia (13), domestic violence (15), unplanned pregnancy, HIV, sexually transmitted diseases (STDs), alcohol use disorder, depression, suicide, and mariticide are among the health risks threatening teenage women (16). The Onset of sexual activity in teenagers often occurs under forced conditions. Hence, the intercourse is against the will of the wife, even when it is legally and religiously allowed. This is more probable when the woman is financially dependent on her husband as she has no way to resist the husband's desire. They sometimes risk even barely talking about using contraceptive methods (17). Most of the conducted studies on marriage, are quantitative and have focused on adult women (18) and we know a little about teenage women perception and experience of marriage and sexual relation before the age of 18 . The results of a 2011 quantitative study by Prakash in India, indicated that early age at marriage had a detrimental effect on the reproductive health of women (19). Bam developed an instrument tailored to the Nepali culture in 2015 , to determine the needs of reproductive and sexual health for students aged 15-19 years. Although, their study population were not married (20). Furthermore, the results of studies in other countries cannot be generalized to the Iranian population due to cultural differences. Ardabil is an ancient city in Iranian Azerbaijan where the primary language of people is Azeri. The average rate of marriage for girls under the age of 15 years is up to $9 \%$ in this province (6). The present study was an attempt to elaborate on teenage women's experience and perception of marriage. The importance of this study lies in the fact that instead of relying on national statistics and quantitative data, a qualitative method and in-depth interviews were used to uncover the inner experience of teenage women. The first author of this article was a female researcher from Ardabil with over 20 years' experience of educational and clinical practice in maternal and child health. She has been closely involved with teenage women and their problems such as high-risk pregnancies, dystocia, still birth, domestic violence etc. She tried to enter into the most hidden aspects of the subjects' lives using a sympathetic approach. The aim of this study was to explore the perceptions of Iranian teenage women about marriage in adolescence. Hopefully, the results can be used to design and develop cultural interventions and improve health programs for these women.

\section{Material and Methods}

\subsection{Design and participants}

A conventional content analysis approach was used in this qualitative study. The participants comprised of 14 teenage married women who were selected purposefully and with maximum variation in all urban-rural healthcare centers ( 4 centers) of Ardabil, Iran. Residing in the urban or rural regions and the duration of marriage as well as the experience of pregnancy, childbirth, and breastfeeding were some of the criteria for purposive sampling.

\subsection{Data collection}

The main data collection method was interview. Data were collected from May 2016 to January 2017. The interviewer was a $\mathrm{PhD}$ candidate of sexual and reproductive health and a university lecturer with over 20 years of experience in maternal health in Iran. Fourteen teenage married women participated in semi-structured, in-depth, individual face to face interviews. To obtain more information, two participants had two interview sessions. The average length of each interview was 60 minutes. Interviews lasted until data saturation. All interviews were audio recorded with the participants' permission in Azeri, and translated into Farsi and English, and then converted to a 
rich text format for the MAXQDA 10 software (VERBI GmbH, Marburg, Germany) to facilitate data management. Some questions which were pilot tested and used in the interviews were as follows:

- May I ask you about your marriage experience?

- Can you please tell me about your feeling or thoughts on marriage in adolescence?

- Can you describe your experiences of sex or your relationship with your husband or your social performance?

\subsection{Data analysis}

The data were analyzed suing the Graneheim and Landman strategies (2004). All interviews were immediately transcribed verbatim. To identify a general sense of the matter, each interview was read several times before analysis. Data were divided into units of meaning that were condensed and labeled by codes. The codes were sorted into subcategories and categories based on their similarities and differences (21).

The first author performed data analysis and any coding dispute was reviewed and discussed by all co-workers.

\subsection{Trustworthiness}

In this study, the Lincoln and Guba guideline was followed to ensure trustworthiness (22). Credibility was established through choosing a capable research approach and expert research team, applying purposeful sampling with maximum variation and immersion in the context of the interviews, member checking, peer checking and employing triangulation with multiple data collection such as field notes and participant diaries, and providing feedback on the findings. To assure dependability and conformability, the external audit trail was done. In addition, a precise final report was provided on the research process to enhance transferability. Authenticity was carried out by peer checking to review interviews, codes and categories extracted by research team. Long-term engagement with the participants, as well as maintaining an ongoing relationship with notes and journals improved the depth of data analysis. Two persons translated the interviews from Azeri to Farsi and English separately, and finally, a third person checked and confirmed the translated versions.

\subsection{Ethical Considerations}

This study was part of the first author's doctoral dissertation with ethics approval from the Ethics Committee of the Research Deputy of Tehran University of Medical Science (decree number = IR.TUMS.REC.1395.2576). All participants were informed about the purpose of the study and assured that their conversations would remain confidential. Permission was obtained from all participants to audio-record the interviews in a private room, and informed consent was taken from all of them. They were also informed of the voluntary nature of participation in this study. Moreover, they had the right to withdraw from the study at any time without any consequences on the services they received.

\section{Results}

The mean age of the participants was 14.9 years ranged between 12 to 18 years and the mean age of their marriage and husbands was 13.2 years ranged between 12 to 16 and 23.7 years ranged between 20 to 27 years, respectively. The duration of marital life ranged from 2 to 36 months. Most of them had junior high school education and were living with father/mother in law. Based on the interviews, three main categories were extracted, of which each consisted of three sub-categories. The main categories included: "a false sense of sexual development," "death of dreams," and "threatened independence" (Table 1).

Table1. Categories and Sub-categories

\begin{tabular}{|l|l|}
\hline Categories & Sub-categories \\
\hline False sense of sexual development & Sexual satisfaction \\
\cline { 2 - 2 } & Sexual dissatisfaction \\
\cline { 2 - 2 } & Coercive sexual intercourse \\
\hline \multirow{2}{*}{ Death of dreams } & Stolen childhood \\
\cline { 2 - 2 } & Heavy burden of marital life \\
\cline { 2 - 2 } & No hope of decent job in future \\
\hline Threatened independence & Insufficient decision-making power \\
\cline { 2 - 2 } & Financial dependence to husband or parents \\
\cline { 2 - 2 } & Forced to leave school \\
\hline
\end{tabular}




\subsection{False sense of sexual development}

The results showed that after marriage and sexual intercourse, the girls entered the world of womanhood and felt complete and grown-up. However, not all the participants had a good feeling about sexual relationship. Some even complained about the painful or coercive nature of their experience and said they did it only to satisfy their husbands. This theme was composed of three subthemes as follows:

\subsubsection{Sexual satisfaction}

Some participants expressed satisfaction with their sexual relationship. A 14 years old participant, married for one year, said about her experience of sex , “...After the first sex, I felt like I was a grown-up and should lead a more respectful life..." A 15-year-old pregnant woman also mentioned her satisfaction with sexual intercourse and stated, "...I am quite OK with my sexual relationship. It is good..."

\subsubsection{Sexual dissatisfaction}

Some of the participants were dissatisfied with their painful and unpleasant sexual experiences and were not eager for sexual intercourse. A 13-year-old woman who married three years ago, gave her opinion saying "...I do not like sex; I would not have married if I knew it was going to be like this..." A 16 year-old participant who had a sixmonth-old baby, said regarding her sexual experience, “...My husband likes sex but I don't; it is all pain for me and nothing interesting. It was very painful during the first month; it is still painful even though I use lubricant and stuff like that..."

\subsubsection{Coercive sexual intercourse}

Many participants were forced to have sex only to satisfy their husband and protect their family. A 16 year-old rural participant with a one-year-old baby, described her feelings about sex as follows, "...I am not interested at all. If it was not for my husband, I would not try it even once a year...". A 14-year-old woman who was pregnant for 28 weeks, shared her first experience with sex as follows, “...I was really frightened and did not allow my husband to do anything; finally, he became angry and forced me. I was scared and cried; my sexual dissatisfaction continues and nothing has changed ever since..."

\subsection{Death of dreams}

Another extracted category was "death of dreams". The participants expressed that they were disappointed and found their dreams had faded away. They missed their childhood and found the responsibilities of a marital life hard to bear. They also lost all hopes of having a good job and a good future. The sub-categories included:

\subsubsection{Stolen Childhood}

The majority of the participants felt that they had lost their childhood, and envied their peers who were lucky to be with their parents and friends. A 14 years old participant who married at the age of 12, about her feelings towards early marriage stated, “...Early marriage is the nastiest thing; I long for my childhood but there is no way to escape; I am expected to act like a grown-up women..." Another woman, aged 16, expressed in this regard, “...I regret my marriage; I wish I was with my family or at school with my friends..."

\subsubsection{Heavy burden of marital life}

Without any clear image about marital life, these women were catapulted to adulthood and forced to accept the responsibilities of a spouse. A 17-year-old woman with a one-year-old girl, explained her three years of experience of marital life as follows, "...Marital life is very hard; cleaning the house, cooking, taking care of the baby, it is just unbearable. Sometimes I wish I was not married..."

\subsubsection{No hope of decent job in future}

Teenage women were deprived of educational and social opportunities and had no hope of a decent job or a good future. A 15-year-old woman who was married for 2 years, said about her future job, “...I do not want to stay home for the rest of my life; I wish I had my own income and job but it is not going to happen..."

\subsection{Threatened independence}

Following their early marriage, most of the women did not have any power or role in making major decisions. Some of them could not even continue their education as their husband or his family did not allow it. Hence, they had no hope for having an income and a better financial and social status in the future. The sub-categories included:

3.3.1. Insufficient decision-making power

Because of their age, low education level, and poor status in the family, these women had a little role in decisionmaking. A 13 years old participant who was married for 1 year stated “...I am in control of nothing at home. I need my mother-in-law's permission even to visit my own mother..." In response to the question whether she wanted a baby or not, another 13-year-old participant said, “...I don't know, you should ask my husband and his family...” 


\subsubsection{Financial dependence to husband or parents}

All of the participants had no income and were totally depended on their husbands or parents. A 16-year-old woman with a five-month-old baby, about her financial status explained, “...My husband does not support all our financial needs and I have no idea how much he earns. My parents support me financially..." A 13-year-old participant, in this regard said, "...My mother buys stuff for me. My husband refuses to give me money and tells me to ask my mother if I need anything..."

\subsubsection{Forced to leave school}

Most of the participants were interested in continuing their education; however, they were forced to leave school after their marriage. A 15-year-old woman who was married for 3 years, said about her interest in education, “...My mother-in-law made me leave school after marriage. To be honest, my husband was not interested either. Anyhow, my mother-in-law argued that it was not easy for them to take me to school and bring me back every day. She said that I could have studied while I was in my father's home if I wanted to."

\section{Discussion}

This study highlights the perception of teenage women about marriage in the Iranian context for the first time. The results reveal that while the teenage women had a false sense of sexual development, early marriage resulted in death of dreams and threatened independence. The results show that after marriage and sexual intercourse, although most participants felt they were complete and deserved more respect, early marriage has led to unpleasant or coercive sexual experiences for some of them. Similarly, Allen et al. (1) found that teenage women endured the health risks and social costs of early and forced marriage and coercive or non-consensual sex. A study in Nigeria showed that early marriage was considered a value, since marriage in local communities improves the social status and dignity of the women (23). The results of a survey in 14 countries with different religions showed that $13-47 \%$ of the girls under 15 years of age who experienced sexual intercourse before and after marriage were forced to have sex, and a similar study in India reported that a large group of young women (14-46\%) experienced coercive sexual intercourse after marriage (24). Therefore, simply getting to puberty cannot be a measure of readiness for marriage and sexual intercourse. Marriage should be delayed until full intellectual and social maturity. The present study also showed that early marriage was a mirage for these girls' dreams. The same conceptions of happiness, respect, and love that were hoped for from the marriage were exactly what the marriage destroyed. Almost all the participants regretted their marriage and longed for their childhood when they lived with their parents. These women mostly complained about the heavy burden of life, vague future, and no hope for finding a good job in the future. Similarly, Zahangir et al. (25) argued that early marriage is a sudden stop to one's childhood, and imposes strict limitations to the choices about the future. The opportunities to play, dream, and acquire knowledge or skills are replaced by responsibilities as a mother, a spouse, and a daughter-in-law. Sing et al. (26) stated that being married is a key obstacle to finding a better job, and Kalb et al. (27) reported that teenage mothers usually have a narrow chance of finding a job, and have poorer health and a lower income compared with women who do not have children. In addition, Barto et al. (28) maintained that challenges such as problems in studying, occupation and financial restrictions reduce the chances in life for teenage women. Since the teenage women do not have essential substructures to reach their goals and suffer from inadequate life skills, marriage should be delayed as long as possible. Another category was "threatened independence". Our participants declared that because of their young age, they had a negligible role in decision-making, were forced to leave school, and were totally dependent on their husband or parents, financially. Similarly, Sharma et al. (9) argued that parents decide when the time is right for their girl to marry and after marriage, due to poor knowledge, low negotiating skills, and social prototype of the ideal women; the bride has no control over her life, desire, or sexual behaviors. Teenage women are legally under the custody of their husbands, which is a great limitation to their freedom and independence (25). Low literacy, unemployment, and financial dependence on the husband or husband's family keep most teenage women from decision making (29). Teenage women have a limited access to financial resources and less power, as compared with adult women, to participate in decisions about their lives (25). Accordingly, Mortimer et al. reported that having no job hinders the development of adulthood characteristics, self-esteem, and independence (30). Therefore, special attention should be paid to the education and empowerment of these women.

Although having high school education is recognized as a right in the Charter of Women's Rights and Responsibilities in Iran, our results showed that teenage marriage was practically an end to education. Almost all women participating in our study were forced to leave school just before or after marriage, while they were very interested in continuing their education. In this regard, Safavi et al. (31) reported that the majority of teenage women only had elementary education. Similarly, Zahangir et al. confirmed their findings, and concluded that early marriage was an obstacle in the path of public education (25). Given that the goal of the present study was to explore 
the perceptions of Iranian teenage women about marriage based on their real experiences, the study findings can be used in designing support, education, empowerment, and counseling programs. Regarding study limitation, a potential limitation was that a number of participants felt embarrassment when talking about sensitive and private issues of their lives, but it was not very hard to win their trust. This study population is very vulnerable and more qualitative research is required to understand these women's health needs.

\section{Conclusions}

Our finding revealed that teenage women could not comprehend opportunities in life. After marriage, they thought they had reached sexual maturity, while early marriage destroyed their dreams and limited their capabilities and decision-making power. The identified categories in this study promote the knowledge and understanding of healthcare professionals and nurses about the complications of child marriage and helps them to provide better support and special care for teenage women in order to prevent the negative consequences of this phenomenon, including a false sense of sexual development, death of dreams, and threatened independence. Policy-makers should adopt a multipronged and culturally sensitive approach to empower these vulnerable women and supply resources to provide them with education, financial support, special health care, and counseling.

\section{Acknowledgments:}

This study was part of the first author's doctoral dissertation. The authors would like to extend their gratitude to Tehran University of Medical Sciences for their financial support. Also, the authors are highly grateful to the participating women for their kind and full cooperation.

\section{Conflict of Interest:}

There is no conflict of interest to be declared.

\section{Authors' contributions:}

All authors contributed to this project and article equally. All authors read and approved the final manuscript.

\section{References:}

1) Allen AA, Adekola PO. Health Implication of child marriage in north-east nigeria. Annals of the University of Oradea, Geography Series. 2017; 1: 54-61.

2) Kamal SMM, Hassan CH, Alam GM, Ying Y. Child marriage in bangladesh: Trends and determinants. J Biosoc Sci. 2015; 47(01): 120-39. doi: 10.1017/S0021932013000746. PMID: 24480489.

3) UNFPA. Marrying Too Young: End Child Marriage. 2012. ISBN: 1618000144.

4) Lotfi R. Early marriage consequences among women. Women \& health. 2011; 2: 67-79.

5) Karrobi M. 1041 Iran civil code Tehran-Iran. Islamic Parliament Research Center Of The Islamic Republic Of IRAN. 2003. Available from: http://rc.majlis.ir/fa/law/show/99682.

6) National Organization for Civil Registration. Statistics of vital events Islamic Republic of Iran: Ministry of Interior. 2015. Available from: https://www.sabteahval.ir/Upload/Modules/Contents/asset99/e-g-94.pdf.

7) Pandey S. Persistent nature of child marriage among women even when it is illegal: The case of Nepal. Child Youth Serv Rev. 2017; 73: 242-7. doi: 10.1016/j.childyouth.2016.12.021.

8) Department of Economic and Social Affairs. Sustainable Development Topics. 2015. Available from: https://sustainabledevelopment.un.org/topics.

9) Sharma R. Decision Making and Role Playing: Young Married Women's Sexual and Reproductive Health in Ahmedabad, India. School of International Development and Global Studies, Ottawa: ProQuest Dissertations Publishing; 2012.

10) Ahmed S, Khan A, Khan S, Noushad S. Eearly marriage; a root of current physiological and psychosocial health berdens. International Journal of Endorsing Health Science Research. 2014; 2(1): 50-3.

11) Nasrullah M, Zakar R, Zakar MZ. Child marriage and its associations with controlling behaviors and spousal violence against adolescent and young women in Pakistan. J of Adolesc Health. 2014; 55(6): 8049. doi: 10.1016/j.jadohealth.2014.06.013. PMID: 25123525

12) Kyari GV, Ayodele J. The Socio-Economic Effect of Early Marriage in North Western Nigeria. Mediterr J Soc Sci. 2014; 5(14): 582. doi: 10.5901/mjss.2014.v5n14p582.

13) Ganchimeg T, Ota E, Morisaki N, Laopaiboon M, Lumbiganon P, Zhang J, et al. Pregnancy and childbirth outcomes among adolescent mothers: a World Health Organization multicountry study. BJOG. 2014; 121(s1): 40-8. doi: 10.1111/1471-0528.12630. PMID: 24641534 
14) Shah IH, Ahman E. Unsafe abortion differentials in 2008 by age and developing country region: high burden among young women. Reprod Health Matters. 2012; 20(39): 169-73. doi: 10.1016/S09688080(12)39598-0. PMID: 22789095

15) Department of Reproductive Health and Research, London School of Hygiene and Tropical Medicine, South African Medical Research Council. Global and regional estimates of violence against women: prevalence and health effects of intimate partner violence and non-partner sexual violence: World Health Organization; 2013: 51.

16) UNICEF. Opportunity in Crisis: Preventing HIV from early adolescence to young adulthood. UNICEF; 2011. ISBN: 9280645862.

17) Mathur S, Greene M, Malhotra A. Too young to wed. The lives, Rights and Health of Young Married Girls. Washington DC: ICRW; 2003: 1-5.

18) Rahmani A, Merghati-Khoei E, Moghadam-Banaem L, Hajizadeh E, Hamdieh M, Montazeri A. Development and psychometric evaluation of the Premarital Sexual Behavior Assessment Scale for Young Women (PSAS-YW): an exploratory mixed method study. Reprod health. 2014; 11: 43. doi: 10.1186/17424755-11-43. PMID: 24924696, PMCID: PMC4067366.

19) Prakash R, Singh A, Kumar Pathak P, Parasuraman S. Early marriage, poor reproductive health status of mother and child well-being in India. J Fam Plann Reprod Health Care. 2011; 37(3): 136-45. doi: 10.1136/jfprhc-2011-0080. PMID: 21628349.

20) Bam K, Haseen F, Kumar R, Newman MS, Chaudhary AH, Thapa R, et al. Perceived Sexual and Reproductive Health Needs and Service Utilization among Higher Secondary School Students in Urban Nepal. Am J Public Health Res. 2015; 3(2): 36-45. doi: 10.12691/ajphr-3-2-1.

21) Graneheim UH, Landman B. Qualitative content analysis in nursing research: consepts, procedures and measures to achieve trustworthiness. Nurse Educ Today. 2004; 24(2): 105-12. doi: 10.1016/j.nedt.2003.10.001. PMID: 14769454.

22) Lincoln YS, Guba EG. Naturalistic Inquiry. Calif, USA: SAGE Publications; 1985.

23) Barroy H, Cortez R, Le Jean N, Wang H. Addressing Adolescent Sexual and Reproductive Health in Niger. 2016. Available from: http://hdl.handle.net/10986/24432.

24) Santhya K, Jejeebhoy SJ, Ghosh S. Early marriage and sexual and reproductive health risks: Experiences of young women and men in Andhra Pradesh and Madhya Pradesh, India: Population Council; 2008. Available from: http://www.popcouncil.org/asia/india.html.

25) Zahangir MS. Early and Very Early Family Formation in Bangladesh. Stockholm University; 2011.

26) Singh A, Revollo PE. Teenage Marriage, Fertility and Well-being: Panel Evidence from India. Oxford Department of International Development (ODID) University of Oxford. 2016. ISBN: 978-1-909403-66-6.

27) Kalb G, Le T, Leung F. Outcomes for teenage mothers in the first years after birth. Australian J Lab Econ. 2015; 18(3): 255.

28) Barto H, Lambert S, Brott P. Career adaptability, resiliency and perceived obstacles to career development of adolescent mothers. The Professional Counselor. 2015; 5(1): 53. doi: 10.15241/hb.5.1.53

29) Shahabuddin A, Nöstlinger C, Delvaux T, Sarker M, Delamou A, Bardají A, et al. Exploring Maternal Health Care-Seeking Behavior of Married Adolescent Girls in Bangladesh: A Social-Ecological Approach. PloS One. 2017; 12(1). doi: 10.1371/journal.pone.0169109. PMID: 28095432, PMCID: PMC5240914

30) Mortimer JT, Kim M, Staff J, Vuolo M. Unemployment, parental help, and self-efficacy during the transition to adulthood. Work and Occup. 2016; 43(4): 434-65. doi: 10.1177/0730888416656904. PMID: 27840554, PMCID: PMC5102391.

31) Safavi H, Saadat H, Minaee M. Live experience of adolescent girls in the role of wife. Women \& health. 2015; 6: 87-106. 